This item was submitted to Loughborough's Research Repository by the author.

Items in Figshare are protected by copyright, with all rights reserved, unless otherwise indicated.

\title{
Modelling the effect of moisture on the depth sensing indentation response of a stereolithography polymer
}

PLEASE CITE THE PUBLISHED VERSION

http://dx.doi.org/10.1016/j.commatsci.2011.01.051

PUBLISHER

(C) Elsevier

VERSION

AM (Accepted Manuscript)

LICENCE

CC BY-NC-ND 4.0

\section{REPOSITORY RECORD}

Altaf, Kazim, lan A. Ashcroft, and Richard J.M. Hague. 2019. "Modelling the Effect of Moisture on the Depth Sensing Indentation Response of a Stereolithography Polymer”. figshare. https://hdl.handle.net/2134/8690. 
This item was submitted to Loughborough's Institutional Repository (https://dspace.lboro.ac.uk/) by the author and is made available under the following Creative Commons Licence conditions.

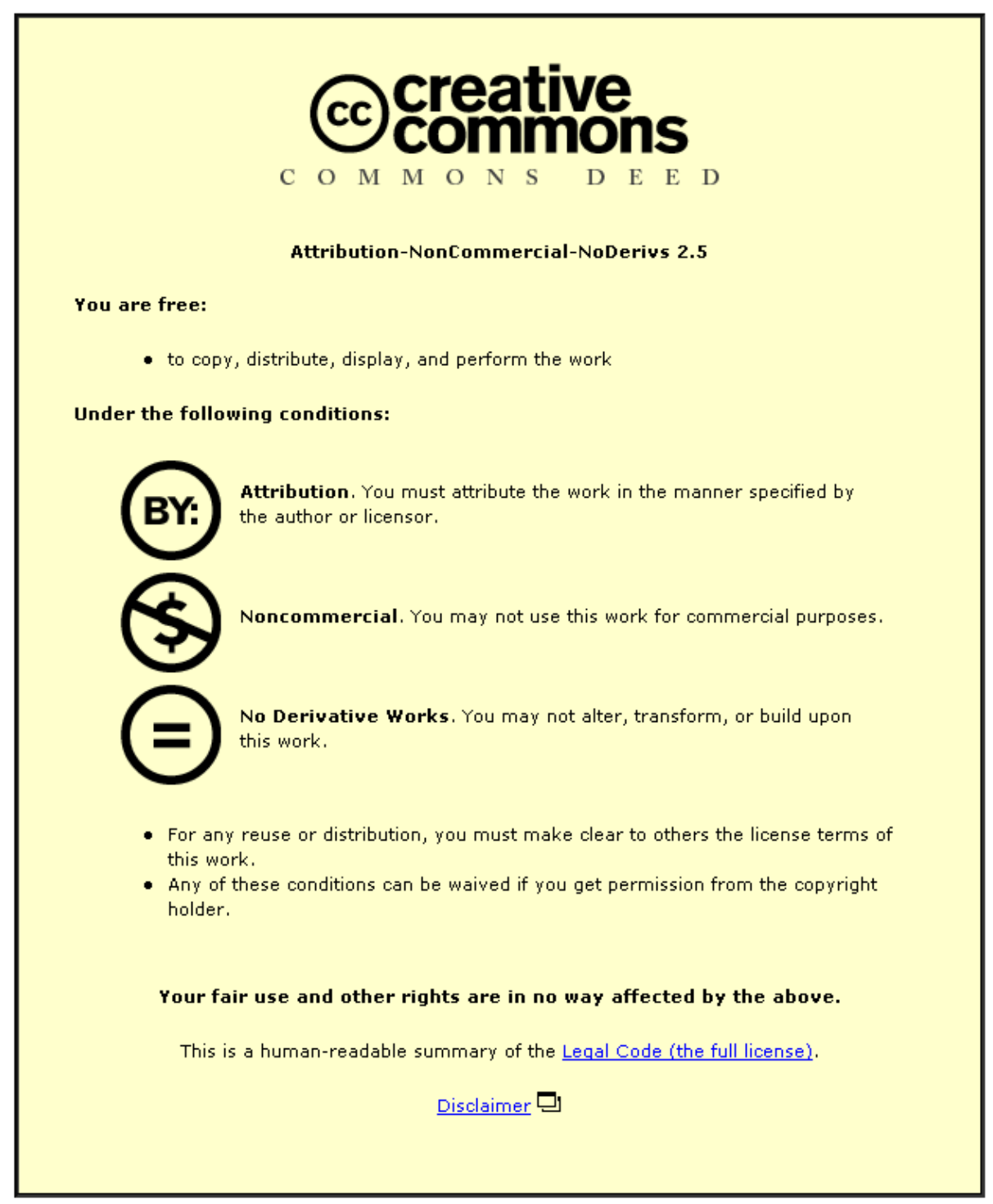

For the full text of this licence, please go to: http://creativecommons.org/licenses/by-nc-nd/2.5/ 


\title{
Modelling the effect of moisture on the depth sensing indentation response of a stereolithography polymer
}

\author{
Kazim Altaf $^{\text {a }}$, Ian A. Ashcroft ${ }^{\mathrm{a}, *}$, Richard Hague ${ }^{\text {a }}$ \\ ${ }^{a}$ Wolfson School of Mechanical \& Manufacturing Engineering, Loughborough University, Leicestershire, LE11 3TU, UK
}

\begin{abstract}
SL (stereolithography) resins are highly hygroscopic and their mechanical properties are significantly affected by the level of moisture in the environment. In addition, the load response of these materials is highly time-dependant, hence, an appropriate rate dependent constitutive model is required to characterise their mechanical behaviour. In this work, the time dependent mechanical behaviour of an SL resin is investigated under varying humidity conditions using DSI (depth sensing indentation) tests. In the experimental study, a DSI system fitted with a humidity control unit was used to explore the influence of moisture on the mechanical properties of a SL resin. Samples were tested with 33.5\%, 53.8\%, 75.3\%, 84.5\% relative humidity $(\mathrm{RH})$ inside the chamber while the temperature was kept constant at $22.5^{\circ} \mathrm{C}$. It was seen that hardness and modulus decreased with increasing absorbed moisture in the resin. The parameters obtained through bulk tests were used to develop a coupled stressdiffusion finite element model incorporating rate dependent material behaviour. It is proposed that this model can be used in predicting the effect of the environment on the performance of SL manufactured components.
\end{abstract}

Keywords: Stereolithography resin; Nanoindentation; Finite element method; Moisture effect; Creep.

\section{Introduction}

SL resins can be used to manufacture parts using an approach to manufacturing called rapid manufacturing (RM) or additive manufacturing (AM) [1]. The SL process is one of the main processes of AM for polymers and is considered highly accurate and consistent [2]. The materials used in the SL process are termed photo-polymers because they are cured using ultra-violet (UV) light [3]. The majority of these SL resins are thermosetting polymers, such as epoxies and acrylates, with the addition of a photo-initiator. Currently, the SL process has

* Corresponding author. Tel.: +44 1509 227535; fax: +44 1509227648.

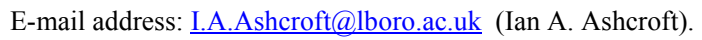


limited use for producing end-use parts owing to the instability of SL materials at high levels of relative humidity and long term UV degradation [4]. Hence, in order to increase the applications of SL as a manufacturing process, materials more suited to a wide variety of enduse applications must be developed. One of the material aspects that require significant development is the environmental stability of the SL materials post-build.

Moisture absorption in polymers leads to a range of effects, such as plasticization by weakening of the intermolecular interactions among the functional groups of the chains $[5,6]$, de-bonding at filler-matrix interfaces [7-9], structural damage, such as micro-cavities or crazes $[10,11]$, and chemical degradation of the polymer matrix due to hydrolysis and oxidation [10-12]. It can also involve the generation of free radicals or other reactive species which may act as plasticizers or reactants [13, 14]. Long-term exposure can involve a decrease in the molecular weight due to chain scission or the breaking of cross-links in the polymer network [15]. Absorbed moisture significantly affects the mechanical properties and glass transition temperature $\left(\mathrm{T}_{\mathrm{g}}\right)$ of polymeric materials $[6,7,9,16,17]$. The changes in mechanical property of polymeric components due to moisture absorption can be related to their performance and can be scrutinized by performing tensile tests, shear tests, microhardness tests, DSI tests etc. on samples after moisture conditioning.

SL parts exhibit spatial variations in properties which can be evaluated by using DSI tests [18]. DSI tests produce quantitative measurements of modulus and hardness with nanoscale spatial resolution by monitoring load and depth during indentation with a sharp or blunt indenter [19]. However, the drawback is in interpreting the data, which is complicated by the complex loading conditions and in polymers moisture absorption and time dependent material response add further complexity.

There have been a few studies on the nanoindentation of polymers in a fully immersed environment [20-24], using liquid cell but, to date, no work has been reported where the effect of varying RH is investigated. In the present work, the time dependent mechanical behaviour of a SL resin is investigated under varying humidity conditions by using a humidity control unit (HCU) to control the environment in a DSI machine. The spatial variations in properties were investigated by testing at different locations and depths. Finite element analysis was performed to simulate nanoindentation under varying relative humidities. In order to extract material properties for use in numerical modelling, bulk mechanical tests and moisture 
absorption tests were performed. A time dependent coupled stress-diffusion model is proposed that can be beneficial in predicting the effect of the environment on the performance of SL manufactured components. The schematic of this research work is summarised in Figure 1. Details of the experiments and FEA are discussed in sections 2 and 3 respectively.

\section{Experimental methods}

\subsection{Material preparation}

The polymer investigated in the present study is epoxy based resin Accura 60, manufactured by 3D Systems (Rock Hill, SC, USA). The samples were manufactured in a flat orientation using an SLA7000 SL machine also manufactured by 3D Systems with 4mm thickness. Thereafter, the samples were washed in chemical solvent; tri-propylene glycol monomethyl ether (TPM) and cleaned with methanol. Finally, UV light post-curing was employed for 30 minutes to stabilise and improve the mechanical properties of the samples. After being subjected to the post manufacture treatments, all the samples were stored in darkness in a dessicator for 20 days to ensure stability before testing.

\section{$2.2 \quad$ Types of experiments}

As shown in Figure 1, three types of experiments were carried. DSI tests were used for investigating spatially resolved material properties. Gravimetric tests were performed to characterise the moisture uptake behaviour and hence calculate the diffusion constants for use in the FEA. Similarly, bulk tensile and compressive tests and creep tensile tests were carried out to generate the mechanical material properties for use in the FEA.

\subsubsection{DSI tests}

DSI tests were performed on 50x50mm dimension samples under $33.5 \%, 53.8 \%, 75.3 \%$ and 84.5\% RH. The NanoTest 600, manufactured by Micro Materials (Wrexham, UK), was used for the experiments. A Berkovich indenter with face angle of $65.3^{\circ}$, giving the same projected area to depth ratio as the Vickers indenter, was used to produce indents. The conditioning of samples inside the machine chamber was carried out by regulating the humidity via a HCU. This unit consists of an ultrasonic humidifier and dehydration unit, which together can be used to set different RH values. The indentation tests were carried every 24 hours for five days under these environments. In DSI tests on polymers, many researchers have found a bulge or "nose" effect during the initial portion of unloading as a result of creep, which can lead to errors in the calculation of contact stiffness and contact depth [25-28]. This effect can 
be minimized in different ways. Most often a dwell/holding time is introduced between the loading and unloading phases [29]. In our present work we have introduced a $300 \mathrm{sec}$ dwell time. To compare quantitatively, experimental parameters were kept the same during all the experiments, with $0.5 \mathrm{mN} / \mathrm{sec}$ loading and unloading rates and a $20 \mathrm{mN}$ maximum load. Five indentations were made $150 \mu \mathrm{m}$ apart, and the average values of hardness and modulus were calculated using the Oliver and Pharr (OP) method [30]. In this method the initial unloading curve is approximated by a power law, as given in Equation 1.

$$
\mathrm{P}=\alpha\left(\mathrm{h}-\mathrm{h}_{\mathrm{r}}\right)^{\mathrm{m}}
$$

Where $P$ is the load, $\alpha$ and $m$ are curve fitting constants, $h$ is penetration depth and $h_{r}$ is the final unloading depth. The derivative of Equation 1 at maximum load is the contact stiffness (S) as shown in Equation 2.

$$
\mathrm{S}=\frac{\mathrm{dP}}{\mathrm{dh}}\left(\mathrm{h}=\mathrm{h}_{\max }\right)=\operatorname{m\alpha }\left(\mathrm{h}_{\max }-\mathrm{h}_{\mathrm{r}}\right)^{\mathrm{m}-1}
$$

The plastic contact depth at maximum load is then calculated from:

$$
\mathrm{h}_{\mathrm{p}}=\mathrm{h}_{\max }-\varepsilon \frac{\mathrm{P}_{\max }}{\mathrm{S}}
$$

Where $\varepsilon$ is a constant that depends on the geometry of indenter, which is 0.75 for the Berkovich indenter. The projected contact area ' $\mathrm{A}_{\mathrm{c}}$ ' is calculated from ' $\mathrm{h}_{\mathrm{p}}$ ' and then used to find hardness ' $\mathrm{H}$ ' as shown in Equation 4.

$$
\mathrm{H}=\frac{\mathrm{P}_{\max }}{\mathrm{A}_{\mathrm{c}}}=\frac{\mathrm{P}_{\max }}{24.5 \mathrm{~h}_{\mathrm{p}}{ }^{2}}
$$

The effective modulus can be calculated from stiffness ' $S$ ' using:

$$
\mathrm{S}=\beta \cdot \frac{2}{\sqrt{\pi}} \mathrm{E}_{\mathrm{eff}} \sqrt{\mathrm{A}}
$$

Where $\beta$ is a correction factor that depends on the type of indenter used, with a value of 1.05 for the Berkovich indenter. We can calculate the modulus, E, of the tested material by using Equation 6:

$$
\frac{1}{E_{\text {eff }}}=\frac{1-v^{2}}{E}+\frac{1-v_{i}^{2}}{E_{i}}
$$

Where subscript ' $i$ ' represents values for the indenter.

\subsubsection{Gravimetric tests}


Gravimetric tests were carried out to characterise moisture uptake in the Accura 60. Curve fitting of this data helped to select an appropriate diffusion model and determine the model parameters, which were later used in the model to carry coupled stress-diffusion FEA. The samples for this test were manufactured with dimensions of $60 \times 60 \mathrm{~mm}$, as recommended in ISO 62 [31]. Five samples were used to obtain an average value for each environment. A digital scale developed by Mettler Toledo Incorporation (Columbus, OH, USA), with an accuracy of $0.1 \mathrm{mg}$ was used to weigh the samples. The samples were conditioned in glass containers and kept at a constant temperature $\left(22.5^{\circ} \mathrm{C} \pm 1\right)$. Specimens were extracted at 4,8 , $12,20,32,44,68$ and $92 \mathrm{hrs}$, and then at time intervals of $24 \mathrm{hrs}$. On extraction of conditioned samples, surface moisture was removed with a clean, dry cloth, and each sample was weighed to the nearest $0.1 \mathrm{mg}$. This was completed within 1 minute of removal from the conditioning environment. The conditioning process was continued for 720 hours. The humidity inside each flask was controlled using saturated salt solutions; magnesium chloride, magnesium nitrate, sodium chloride and potassium chloride were used to give relative humidities of $33.5 \%, 53.8 \%, 75.3 \%$ and $84.5 \%$ respectively, with \pm 1 variation. A graphical plot of water uptake $\left(M_{t} / M_{\infty}\right)$ against $(\sqrt{t} / l)$ was made for each environment, where $M_{t}$ indicates the mass of the total amount of penetrant absorbed at time $t ; M_{\infty}$ is the corresponding mass at saturation and $l$ is the specimen thickness. The commercial mathematical programming package Mathcad (by PTC, Needham, USA) was used to obtain the best fit diffusion parameters for the experimental results by using least square curve fitting technique for Fickian and dual Fickian diffusion models, as given in Equation 7 and 8 respectively.

$$
\begin{gathered}
\frac{M_{t}}{M_{\infty}}=1-\sum_{n=0}^{\infty} \frac{8}{(2 n+1)^{2} \pi^{2}} e^{\left[\frac{-D(2 n+1)^{2} \pi^{2} t}{4 l^{2}}\right]} \\
M_{t}=M_{1 \infty}\left[1-\sum_{n=0}^{\infty} \frac{8}{(2 n+1)^{2} \pi^{2}} e^{\left[\frac{-D_{1}(2 n+1)^{2} \pi^{2} t}{4 b^{2}}\right]}\right]+ \\
M_{2 \infty}\left[1-\sum_{n=0}^{\infty} \frac{8}{(2 n+1)^{2} \pi^{2}} e^{\left[\frac{-D_{2}(2 n+1)^{2} \pi^{2} t}{4 b^{2}}\right]}\right]
\end{gathered}
$$

\subsubsection{Bulk mechanical testing}


In order to extract overall mechanical behaviour of materials, bulk mechanical tests; tensile and compressive tests, were performed. ASTM D638 and ASTM D695 standards were used for defining dimensions and testing methods of samples for tensile and compressive tests respectively $[32,33]$. The specimens were built in an edge orientation using the SL machine, to avoid build failure. Samples were preconditioned using the techniques described in Section 2.2.2. Both uniaxial tensile and compressive tests were carried at $0.1 \mathrm{~mm} / \mathrm{min}$ displacement rate at $22.5^{\circ} \mathrm{C}( \pm 1)$ using universal testing machine Instron - 3366 (Instron Corporation, Norwood, MA, USA) with a maximum load capacity of $10 \mathrm{kN}$. Five tests were performed to obtain an average value. Stress-strain relations, yield stress and modulus values extracted from these experiments were used in defining the elastic-plastic material model for FEA. Tensile creep tests were also performed on that machine at five different stress levels, 26 MPa, $32 \mathrm{MPa}, 38 \mathrm{MPa}, 44 \mathrm{MPa}$ and $50 \mathrm{MPa}$. as per ASTM D2990 [34] testing standard. Data from these experiments was analysed using a creep power law relationship between the strain rate $(\varepsilon)$ and applied stress $(\sigma)[35]$ as:

$$
\dot{\varepsilon}=A \sigma^{\mathrm{m}}
$$

Where 'A' and ' $\mathrm{m}$ ' are the empirical constants that can be calculated by plotting $\log (\dot{\varepsilon})$ against $\log (\sigma)$. The constants calculated were used in the FEA model to define rate dependent behaviour.

\section{Finite Element Simulation of the effect of moisture on DSI}

MSC Marc Mentat 2007, a nonlinear FEA program, by MSC Software Corporation (Santa Ana, CA, USA), was used to model load-deformation behaviour of the Accura 60 resin during indentation. 2D conical analyses were carried using a $70.3^{\circ}$ half-included angle, which provides the same area to depth ratio as a Berkovich indenter. The indenter was taken as a rigid body and the sample as deformable while friction between their interface was neglected. In the DSI experiments, the indentation area was small compared to the size of sample and if the same size of sample was modelled it would result in excessive computational time and cost. Thus sensitivity to far field analyses was carried to obtain the optimum size of model that provides negligible displacement and stresses at boundaries with the smallest computation time. Results showed $30 \mu \mathrm{m} \times 20 \mu \mathrm{m}$ as the optimum choice and hence a model of this size was used in all the FEA work. To obtain accuracy in the results, a fine mesh was 
employed in the contact area while a coarser mesh was used elsewhere. Axisymmetric eight node quadratic elements with reduced integration were used. Mesh sensitivity analyses were performed by varying element size. From the results $0.5 \mu \mathrm{m} \times 0.3 \mu \mathrm{m}$ was selected as an optimum element size for all the analyses. Figure 2 shows details of the FE model used in the present work. The constraint in the y direction at the bottom of the figure represents the axis of the axi-symmetry.

The motion of the indenter was defined as load controlled by defining a control node at the point where the point load shown in Figure 2 was applied. In the experiments, an indenter stays in contact with the sample for a few seconds before application of the load, so the same conditions were implemented in the FE model. During DSI experiments, the specimen was glued at its base to restrict its motion in the direction of motion of the indenter (x-axis) and therefore similar boundary conditions were imposed in the FE model. During experiments it was found that the properties of the material are practically the same in all directions and thus the material was defined as isotropic. Elastic-plastic properties were defined by using true stress vs. plastic strain data calculated from the bulk mechanical tests. In order to account for the hydrostatic stress sensitivity found in Accura 60, a linear Mohr-Coulomb (LMC) yield criteria was used. Rate dependency of the resin was modelled by using the power law creep model described in Section 2.2.3. Hence, deformation under the load is the sum of time independent elastic and plastic components from LMC material model and a time dependent component from the power law creep model. Full Newton-Raphson iterative procedure, with an adaptive load step scheme was employed.

In order to generate simulated load-depth plots of indentation under various $\mathrm{RH}$, coupled stress-diffusion finite element analyses were performed. In MSC Marc Mentat software, there is no direct option for moisture transport analysis, however, moisture diffusion can be analysed by adapting the mathematical equations of heat conduction, derived by Fourier, as described by Crank [36]. Therefore, heat transfer analyses in conjunction with stress analyses were used to carry out couple analyses. The diffusion parameters, calculated from the gravimetric test data were used in the diffusion analysis.

\section{Results and discussion}

\subsection{Experimental DSI tests}


Figure 3 shows a comparison of load-depth plot for samples conditioned for a day at different environments. It can be seen that indentation penetration depth has increased with increasing $\mathrm{RH}$. This is because an increase in RH in the environment results in the absorption of more moisture in the polymers. The absorbed moisture decreases the intermolecular forces, lowers the glass transition temperature $\left(\mathrm{T}_{\mathrm{g}}\right)$ and, hence, softens the surface, leading to a decrease in resistance to indentation $[20,21,37]$.

Figures 4 and 5 show plots of the calculated indentation hardness, H, and modulus, E, as a function of conditioning time for various environments. It is interesting to see that values of both $\mathrm{E}$ and $\mathrm{H}$ are not significantly affected at $33.5 \% \mathrm{RH}$. This indicates that the saturated moisture content associated with $33.5 \% \mathrm{RH}$ at $22.5^{\circ} \mathrm{C}$ has little effect on the polymers mechanical properties. However, at $75.3 \%$ and $84.5 \% \mathrm{RH}$, the values of $\mathrm{E}$ and $\mathrm{H}$ fall significantly with conditioning time. We know that calculations of $\mathrm{E}$ and $\mathrm{H}$ are dependent on value of contact depth [30]. The rate of decrease in E and $H$ decreases with time as the surface layers reach an equilibrium moisture content for that penetration level of RH.

\subsection{Diffusion modelling}

Figure 6 shows the comparison of results of fitting the Fickian diffusion model (Equation 1) and dual Fickian model (Equation 2) to the gravimetric experimental data at $84.5 \% \mathrm{RH}$. It is obvious from the figure that with Fickian model, although the equation adequately fits the early stages of water uptake, it provides a poor fit to the data above $60-70 \%$ of the equilibrium uptake. This type of moisture uptake, that has a Fickian-like shape but approaches equilibrium more slowly than predicted by the Fickian model, is termed pseudo-Fickian behaviour [36], and is common in epoxy resins [38]. The dual Fickian model, based on the summation of two Fickian models [39], fits the experimental data very well and was used in FEA model. The Fickian and dual Fickian diffusion constants under various RH are given in Table 1.

\subsection{FEA analyses}

Results from the coupled stress-diffusion FE analyses, performed by incorporating transient moisture diffusion into contact stress analyses of the indentation process are discussed in this section. Load-depth curves from FEA model are compared with experimental curves at $33.5 \%, 53.8 \%$ and $84.5 \% \mathrm{RH}$ environments in Figure 7 . It can be seen that there is an excellent match with the experimental curves, except during the last part of unloading. This 
variation may be attributed to the assumption of frictionless contact and inability of the creep power law to model viscoelastic recovery during unloading. Another reason for variation in the curves could be the difference between the actual tip geometry used in experiments and the ideal conical indenter used in modelling. However, significant parameters such as the indentation depth under maximum load, creep in the dwell period and the initial unloading slope are predicted very accurately by the model for all the conditions.

A series of FE analyses were undertaken to predict the value of $\mathrm{H}$ as a function of conditioning time and indentation depth. The contact area $\mathrm{A}_{\mathrm{c}}$ was found from the FEA by calculating contact depth $h_{p}$. The calculated values were then used in Equation 4 to find hardness H. Figure 8 shows a comparison of values of $\mathrm{H}$ from FEA and the DSI experiments, measured periodically for 5 days under $84.5 \%$ RH conditioning. Normalised moisture uptake data is also plotted against conditioning time in that figure. Results show a decrease in the value of $\mathrm{H}$ with time as a result of an increase in moisture content in the surface layers. It can be seen in Figure 8 that the prediction from the FEA compares well with the experimental results. Figure 9 compares values of $\mathrm{H}$ from FEA and DSI tests at various indentation depths after 12 hours of conditioning at $84.5 \% \mathrm{RH}$. The normalised moisture concentration profile calculated from the FEA diffusion analyses is also plotted in the figure. The values of $\mathrm{H}$ are low at shallow depths due to the influence of higher moisture content; however, they increase at higher depths as the material indented has lower average moisture content. Again, there is an excellent agreement between the experimental and FEA predicted results.

\section{Summary and Conclusions}

- The effect of moisture, present in the environment, on the mechanical properties of a polymeric SL resin has been investigated using DSI. Experimental results show that the mechanical properties of the polymer are highly dependent on the $\mathrm{RH}$ of the environment and that a DSI fitted with HCU is capable of investigating this relationship. The results also indicate that care should be taken to control $\mathrm{RH}$ when conducting DSI experiments if the results are to be reliable. The advantage of DSI over other techniques is the small amount of material is required, properties can be spatially resolved and the variation of properties with depth below a surface can be investigated.

- $\quad$ Results from the FEA show that load-depth response from the DSI of polymers under varying $\% \mathrm{RH}$ can be predicted with good accuracy by employing coupled stress-diffusion 
FEA modelling together with appropriate time dependent material and diffusion models. It is demonstrated that values of indentation hardness can be accurately predicted under various environments and depths using the proposed FEA model. This method involves calculating plastic contact depth from the simulation results. Values of $\mathrm{H}$ from the FEA show a good fit with the experimental data. Hence, this model can be used in predicting the effect of the environment on the performance of SL manufactured components.

\section{References}

[1] D.W. Rosen, Comput. Aided Des. Applic. 4 (2007) 585-594.

[2] R. Hague, I. Campbell, P. Dickens, Proc. Inst. Mech. Eng. Part C 217 (2003) 25-30.

[3] M. Wu, W. Zhao, Y. Tang, D. Li, B. Lu, Rapid Prototyping Journal 7 (2001) 268-274.

[4] X.Y. Liu, J. Jiang, Rapid Prototyping Journal 9 (2003) 88-94.

[5] K. Ivanova, R. Pethrick, S. Affrossman, Polymer 41 (2000) 6787-6796.

[6] Y. Park, J. Ko, T.K. Ahn, S. Choe, J. Polym. Sci., Part B: Polym. Phys. 35 (1997) 807815.

[7] M. Bowditch, Int. J. Adhes. Adhes. 16 (1996) 73-79.

[8] K. Kasturiarachchi, G. Pritchard, J. Mater. Sci. 20 (1985) 2038-2044.

[9] T. Kumazawa, M. Oishi, M. Todoki, IEEE Trans. Dielectr. Electr. Insul. 1 (1994) 133138.

[10] A. Apicella, L. Nicolais, G. Astarita, E. Drioli, Polymer 20 (1979) 1143-1148.

[11] Y. Diamant, G. Marom, L.J. Broutman, J. Appl. Polym. Sci. 26 (2003) 3015-3025.

[12] S.H. Hamid, second ed., Marcel Dekker, New York, 2000.

[13] J.E. Ritter, J.R. Fox, D.I. Hutko, T.J. Lardner, J. Mater. Sci. 33 (1998) 4581-4588.

[14] J. Verdu, L. Salmon, F. Thominette, M.F. Pays, Composites Science and Technology 57 (1997) 1119-1127.

[15] E.L. McKague Jr, J.D. Reynolds, J.E. Halkias, J. Appl. Polym. Sci. 22 (2003) 1643-1654.

[16] L.M. Butkus, P.D. Mathern, W.S. Johnson, J. Adhes. 66 (1998) 251-273.

[17] S. St. Lawrence, J.L. Willett. C.J. Carriere, Polymer 42 (2001) 5643-5650.

[18] J. Tezcan, K.J. Hsiao, Eng. Struct. 30 (2008) 2206-2210. 
[19] P.K. Zysset, X.E. Guo, C.E. Hoffler, K.E. Moore, S.A. Goldstein, J. Biomech. 32 (1999) 1005-1012.

[20] I.A. Ashcroft, G.M. Spinks, J. Mater. Res. 11 (1996) 529-536.

[21] G.A. Bell, D.M. Bielinski, B.D. Beake, J. Appl. Polym. Sci. 107 (2008) 577-582.

[22] B. Yang, W.M. Huang, C. Li, J.H. Chor, Eur. Polym. J. 41 (2005) 1123-1128.

[23] R. Akhtar, S. Morse, P.M. Mummery, J. Mater. Res. 844 (2005) 15.

[24] S. Hengsberger, A. Kulik, P.H. Zysset, Bone 30 (2002) 178-184.

[25] Y.C. Lu, G.P. Tandon, D.C. Jones, G.A. Schoeppner, Mech. Time-Depend. Mater. 13 (2009) 245-260.

[26] A.H.W. Ngan, B. Tang, J. Mater. Res. 17 (2002) 2604-2610.

[27] Y.T. Cheng, C.M. Cheng, J. Mater. Res. 20 (2005) 1046-1053.

[28] B.J. Briscoe, L. Fiori, E. Pelillo, J. Phys. D: Appl. Phys. 31 (1998) 2395.

[29] T. Chudoba, F. Richter, Surf. Coat. Technol. 148 (2001) 191-198.

[30] W.C. Oliver, G.M. Pharr, J. Mater. Res. 7 (1992) 1564-1583.

[31] ISO 62, International Standard, Plastics - Determination of Water Absorption, second ed., 2008.

[32] ASTM D638, Standard test method for tensile properties of plastics, 2008.

[33] ASTM D695, Standard test method for compressive properties of rigid plastics, 2008.

[34] ASTM 2990, Standard test methods for tensile, compressive, and flexural creep and creep-rupture of plastics, 2009.

[35] I. Ashcroft, P. Briskham, in: D.A. Dillard (Ed.), Woodhead Publishing Limited, Cambridge, UK, 2010, pp. 468-511.

[36] J. Crank, second ed., 1979.

[37] Z. Gaofei, K. Yilan, S. Jing, Q. Qinghua, W. Huaiwen, F.U. Donghui, Sci. China, Ser. E Eng. Mater. Sci. 47 (2004) 595-607.

[38] M.M.A. Wahab, I.A. Ashcroft, A.D. Crocombe, S.J. Shaw, J. Adhes. 77 (2001) 43-80.

[39] W.K. Loh, A.D. Crocombe, M.M. Abdel Wahab, I.A. Ashcroft, Int. J. Adhes. Adhes. 25 (2005) 1-12. 


\begin{tabular}{|c|c|c|c|c|}
\hline & \multicolumn{4}{|c|}{ Relative Humidity } \\
\hline & $33.5 \%$ & $53.8 \%$ & $75.3 \%$ & $84.5 \%$ \\
\hline $\mathrm{M}_{\infty}(\mathrm{wt} . \%)$ & 0.937 & 2.118 & 3.187 & 3.335 \\
\hline $\mathrm{D}\left(\mathrm{cm}^{2} / \mathrm{s}\right)$ & $9.772 \times 10^{-8}$ & $8.535 \times 10^{-8}$ & $7.541 \times 10^{-8}$ & $6.937 \times 10^{-8}$ \\
\hline$M_{1 \infty}(w t . \%)$ & 0.763 & 1.467 & 1.646 & 1.211 \\
\hline $\mathrm{M}_{2 \infty}(\mathrm{wt} . \%)$ & 0.275 & 0.729 & 1.437 & 2.209 \\
\hline $\mathrm{D}_{1}\left(\mathrm{~cm}^{2} / \mathrm{s}\right)$ & $6.019 \times 10^{-8}$ & $6.725 \times 10^{-8}$ & $7.263 \times 10^{-8}$ & $9.743 \times 10^{-8}$ \\
\hline $\mathrm{D}_{2}\left(\mathrm{~cm}^{2} / \mathrm{s}\right)$ & $3.314 \times 10^{-8}$ & $4.176 \times 10^{-8}$ & $5.682 \times 10^{-8}$ & $6.754 \times 10^{-8}$ \\
\hline
\end{tabular}

1 Table 1. Fickian and dual-Fickian model constants for $4 \mathrm{~mm}$ thick Accura 60 samples at various $\mathrm{RH}$ at $22.5^{\circ} \mathrm{C}$. 


\section{Table Caption:}

Table 1: $\quad$ Fickian and dual-Fickian model constants for $4 \mathrm{~mm}$ thick Accura 60 samples at various $\mathrm{RH}$ at $22.5^{\circ} \mathrm{C}$.

\section{Figures Caption:}

Figure 1: $\quad$ Schematic of methodology of research.

Figure 2: $\quad$ FE model showing geometry and mesh details.

Figure 3: Comparison of load-depth plot of samples conditioned by HCU for a day under various \% RH and tested under the same conditioning environments.

Figure 4. Indentation hardness as function of time after conditioning and testing under various humid environments regulated by HCU.

Figure 5. Indentation modulus as function of time after conditioning and testing under various humid environments regulated by HCU.

Figure 6. Experimental, Fickian and dual-Fickian models curves for Accura 60 samples conditioned at $84.5 \% \mathrm{RH}$ at $22.5^{\circ} \mathrm{C}$.

Figure 7: Comparison of load-depth plots of FEA with experiments of samples conditioned by HCU for a day under various \% RH and tested under the same conditioning environments.

Figure 8. Comparison of hardness calculated from FEA modelling with experiments after various days of conditioning and testing under $84.5 \% \mathrm{RH}$.

Figure 9. Comparison of hardness calculated from FEA modelling with experiments and moisture concentration profile at various depths inside the specimen after 12 hours at $84.5 \% \mathrm{RH}$. 


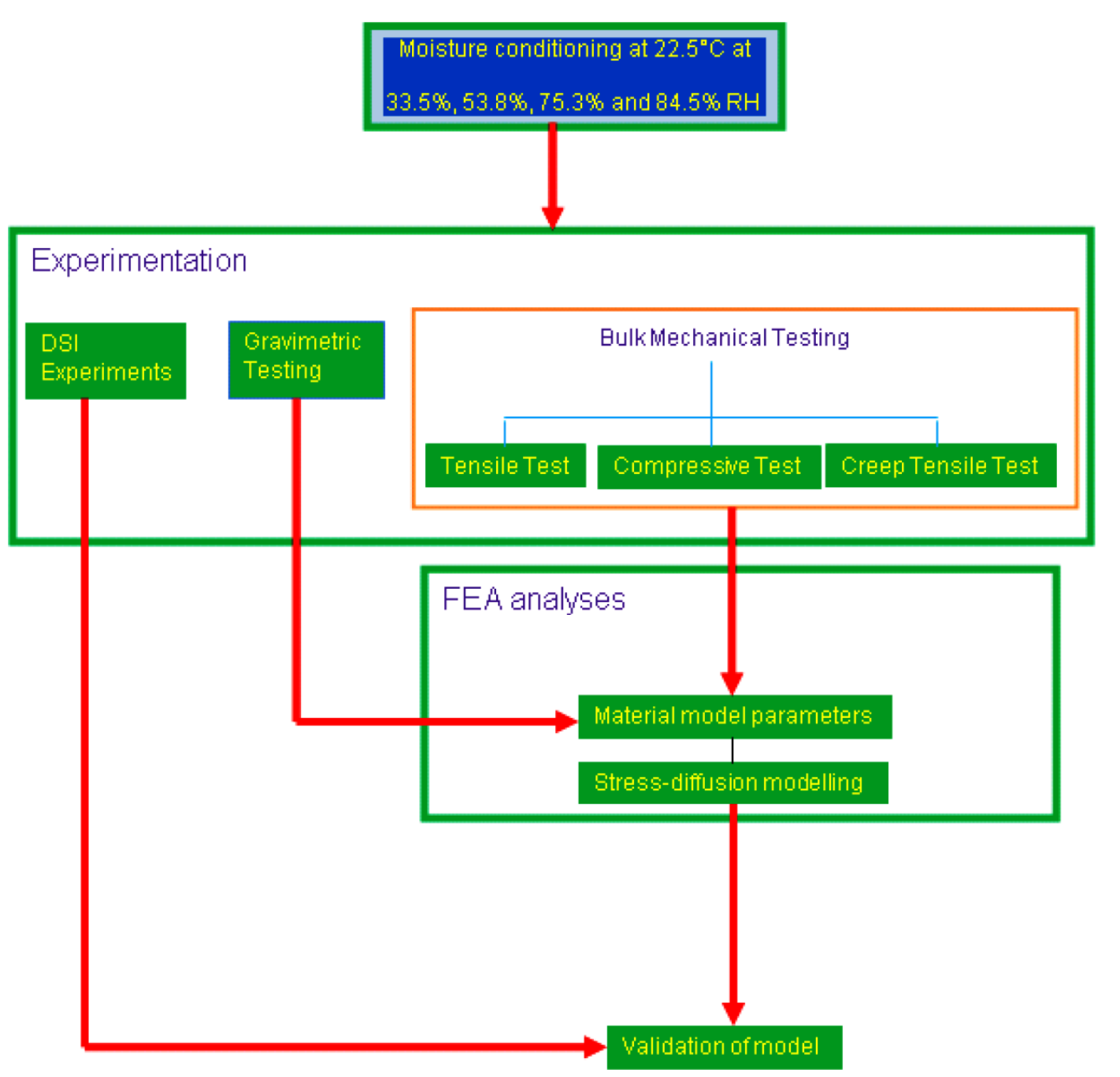

Figure 1: Schematic of methodology of research. 


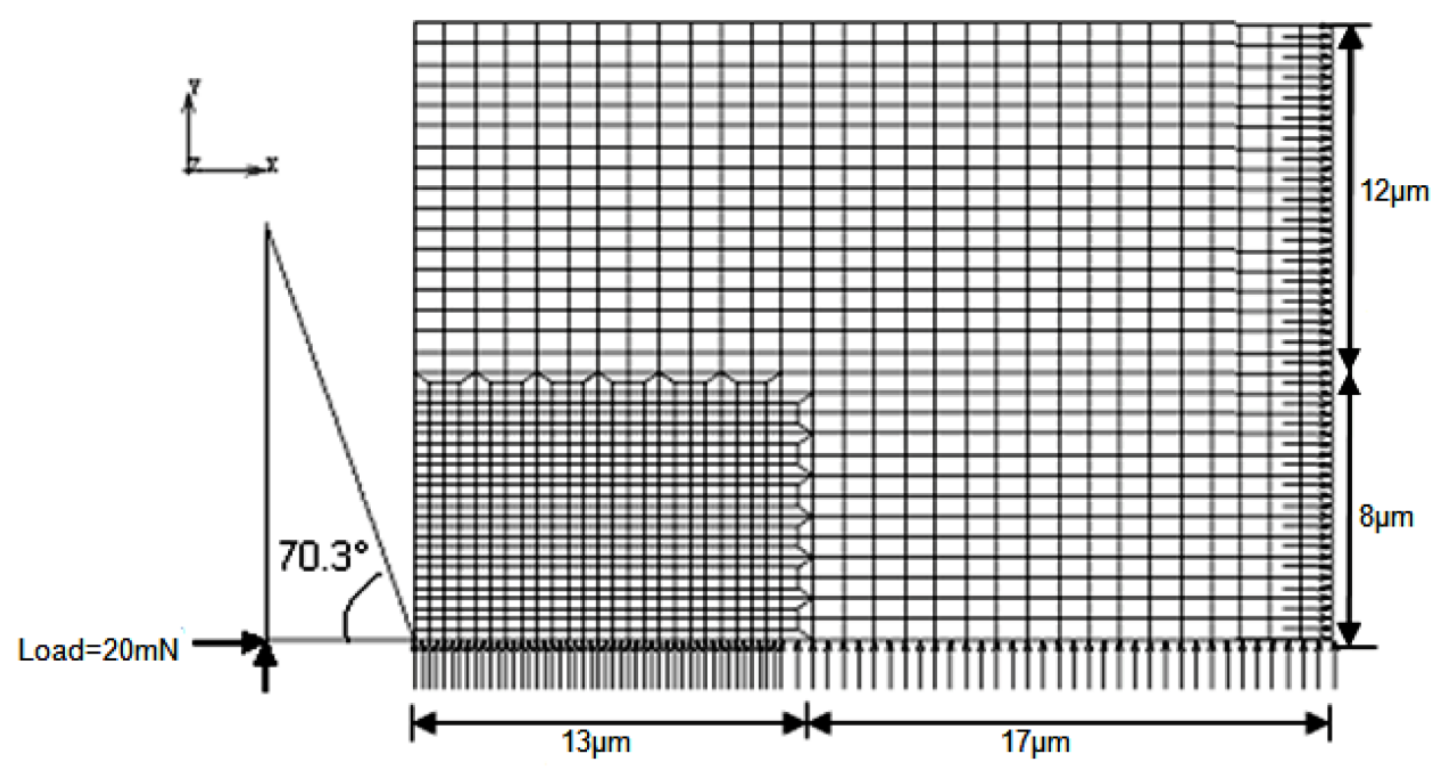

Figure 2: FE model showing geometry and mesh details. 


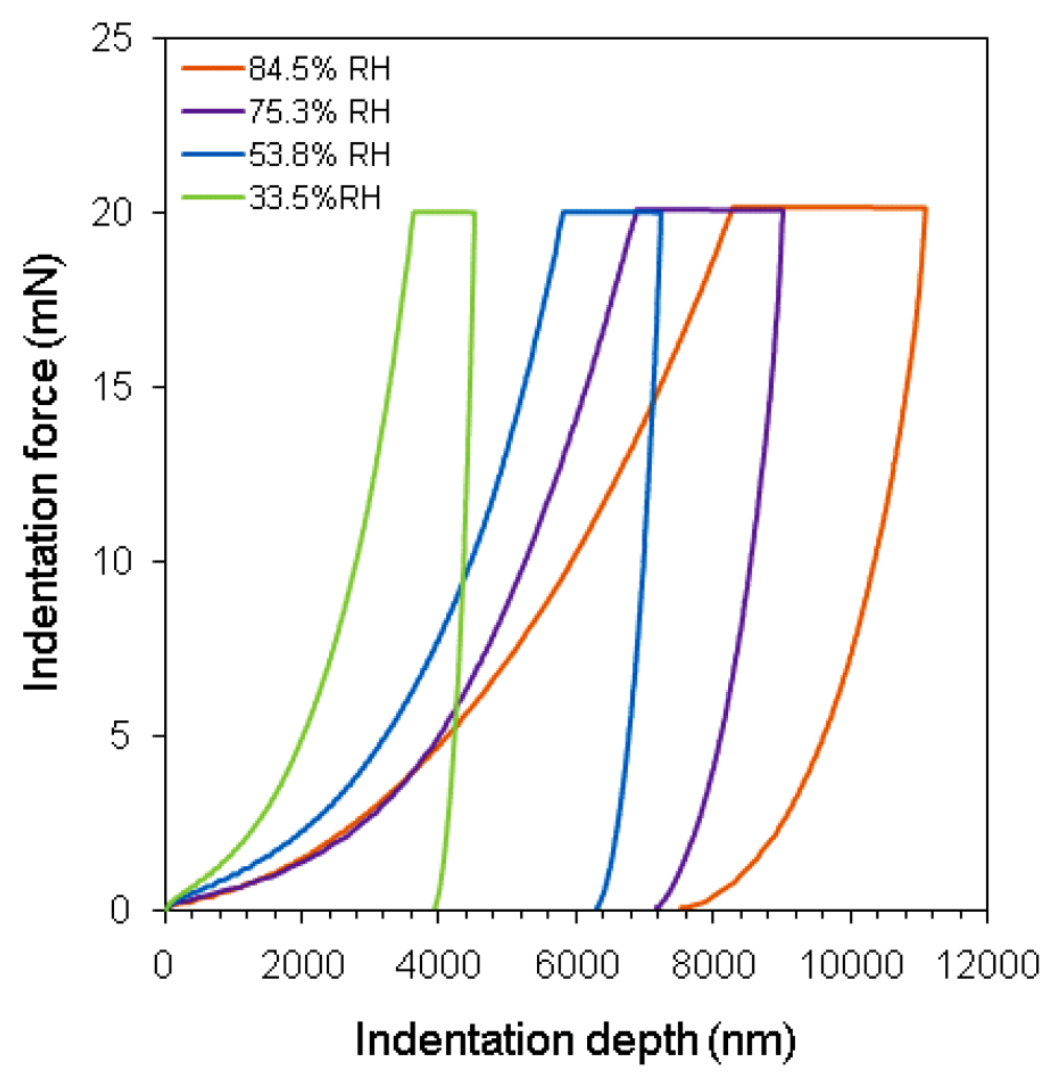

Figure 3: Comparison of load-depth plot of samples conditioned by HCU for a day under various $\% \mathrm{RH}$ and tested under the same conditioning environments. 


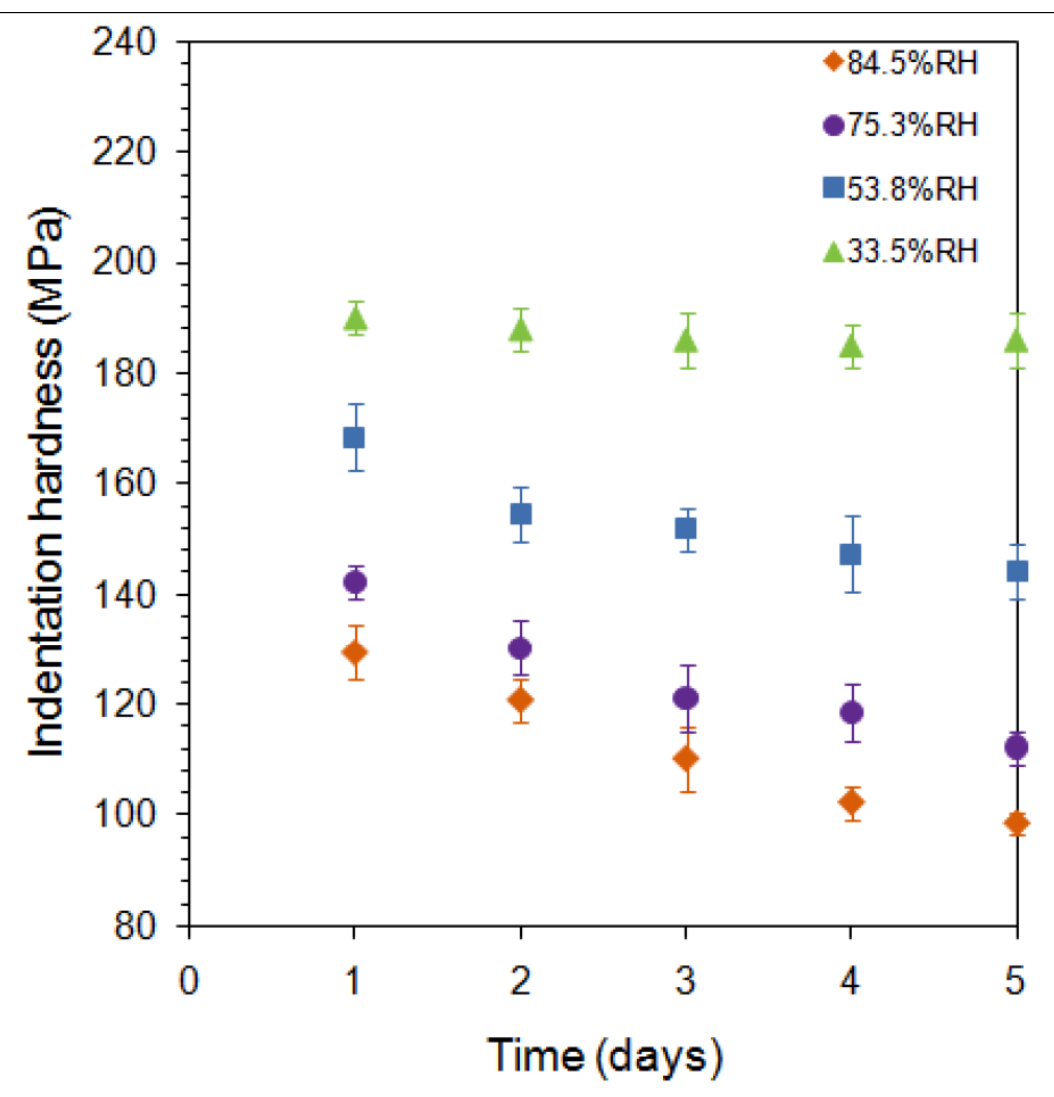

Figure 4. Indentation hardness as function of time after conditioning and testing under various humid environments regulated by HCU. 


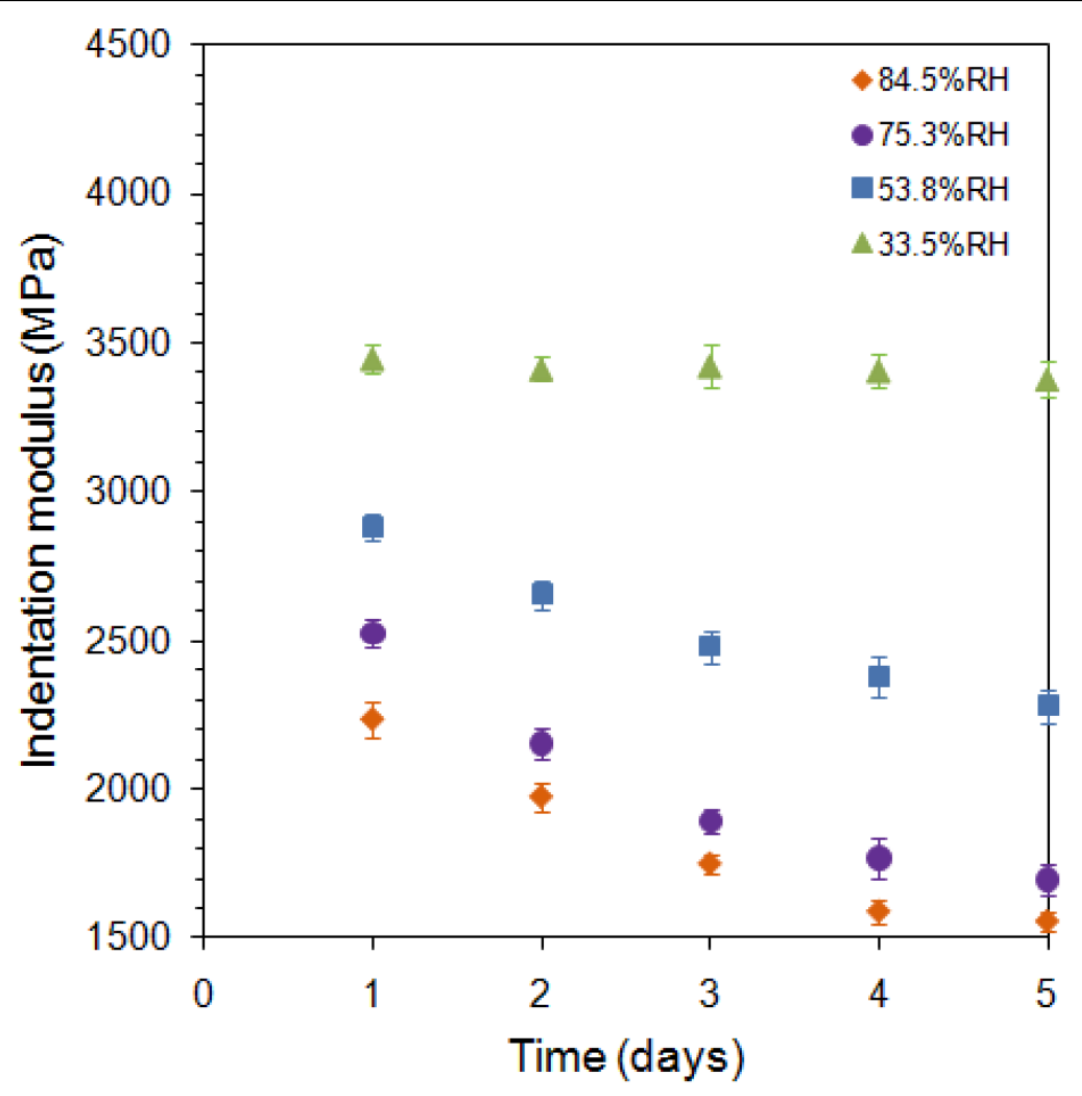

Figure 5. Indentation modulus as function of time after conditioning and testing under various humid environments regulated by HCU. 


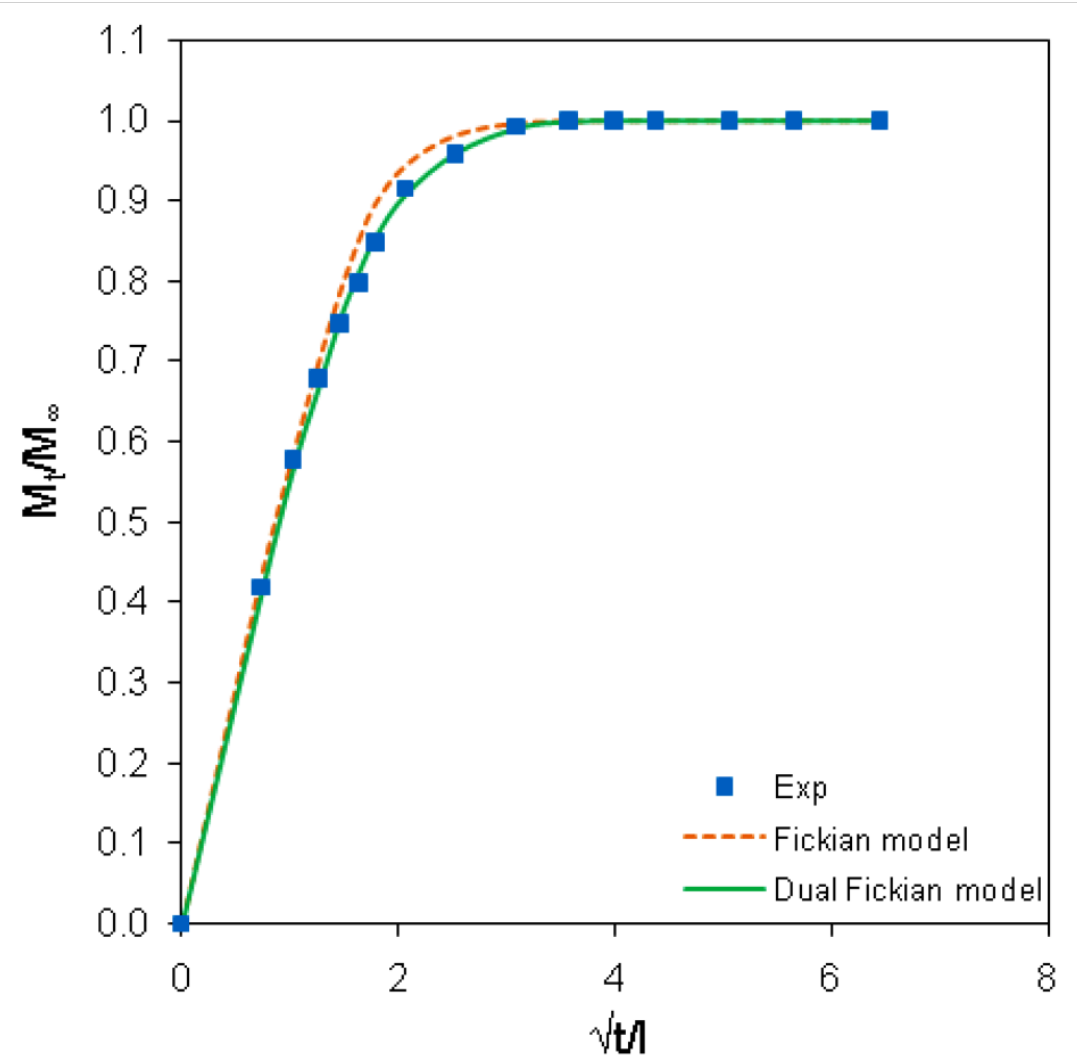

Figure 6. Experimental, Fickian and dual-Fickian models curves for Accura 60 samples conditioned at $84.5 \% \mathrm{RH}$ at $22.5^{\circ} \mathrm{C}$. 


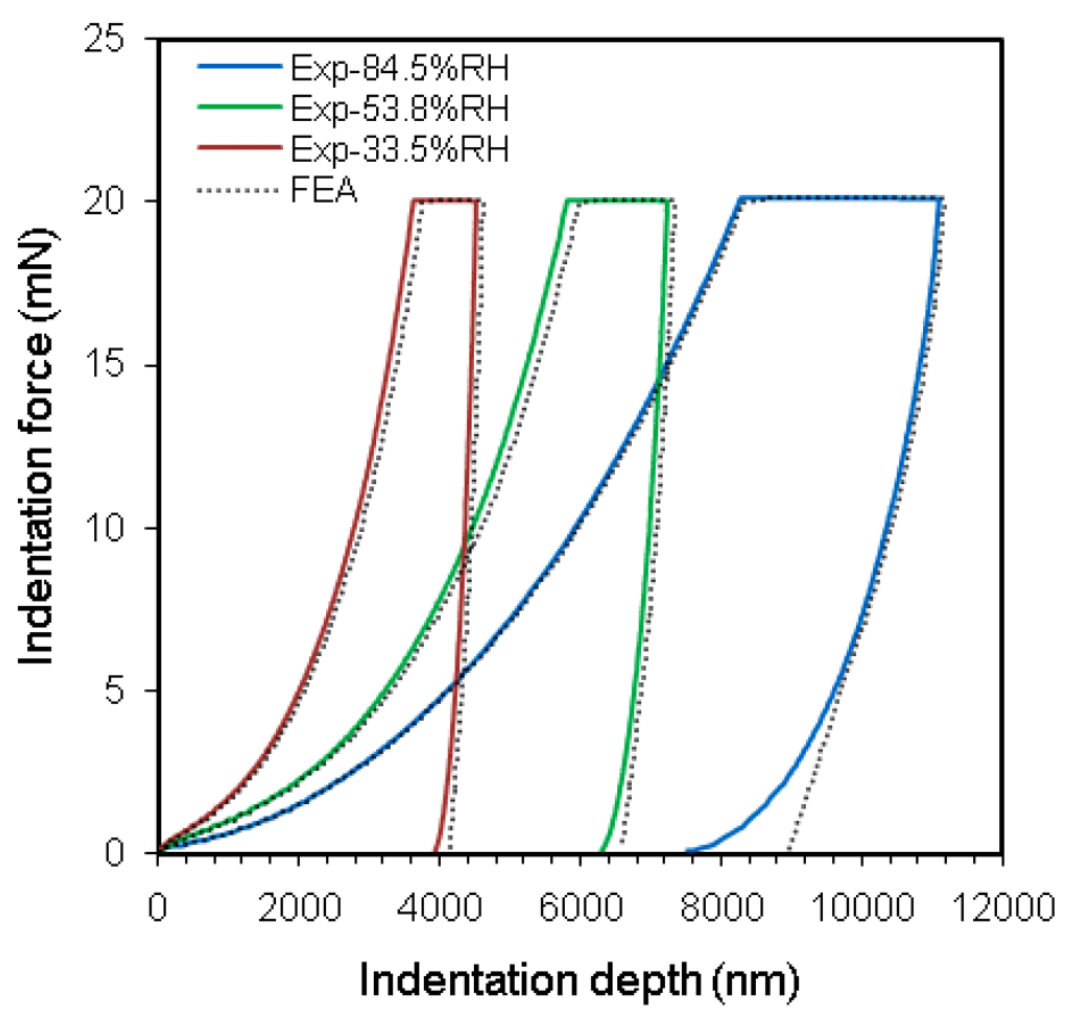

Figure 7: Comparison of load-depth plots of FEA with experiments of samples conditioned by HCU for a day under various $\%$ RH and tested under the same conditioning environments. 


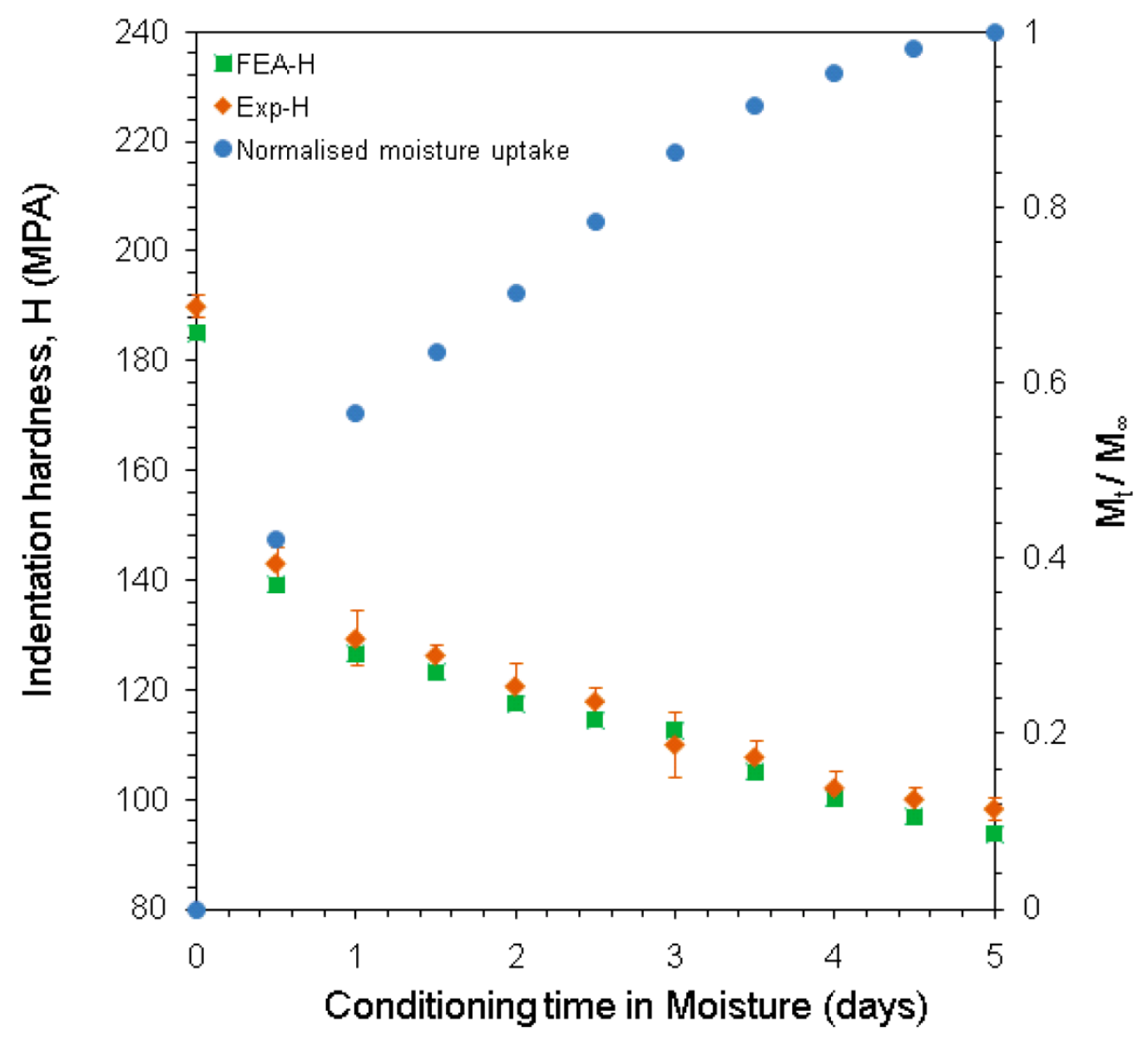

Figure 8. Comparison of hardness calculated from FEA modelling with experiments after various days of conditioning and testing under $84.5 \% \mathrm{RH}$. 


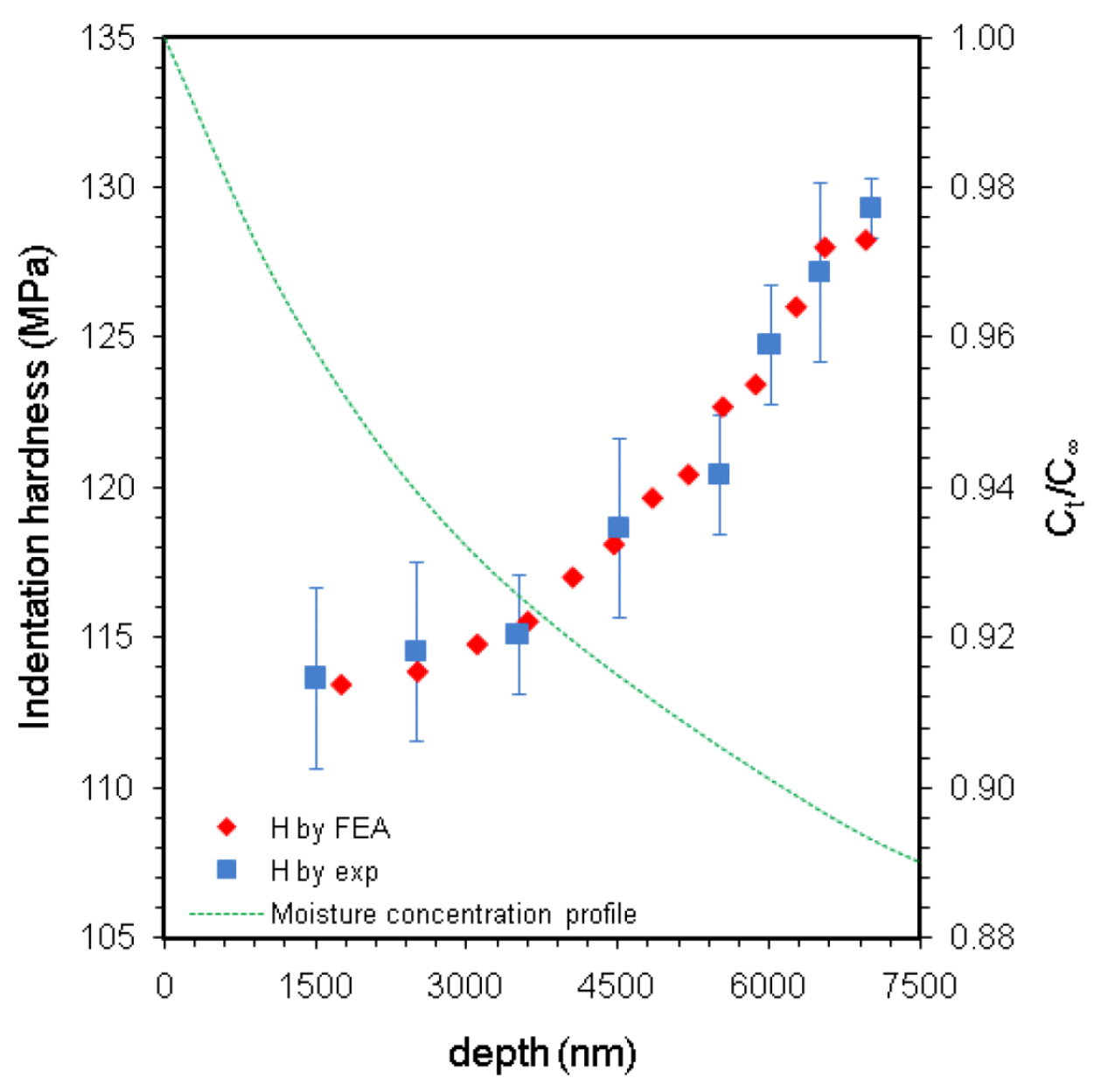

Figure 9. Comparison of hardness calculated from FEA modelling with experiments and moisture concentration profile at various depths inside the specimen after 12 hours at $84.5 \%$ RH. 